\title{
Development of donor cell leukemia following peripheral blood stem cell transplantation for severe aplastic anemia: A case report
}

\author{
HONGBING MA and TING LIU
}

\author{
Department of Hematology, West China Hospital, Sichuan University, Chengdu, Sichuan 610041, P.R. China
}

Received December 24, 2014; Accepted January 21, 2016

DOI: $10.3892 / 01.2016 .4452$

\begin{abstract}
Donor cell leukemia (DCL) is a rare complication of hematopoietic stem cell transplantation (HSCT) which occurs in $~ 5 \%$ of all leukemic relapses. In the English literature, $>60$ cases of DCL have been reported, however, only two cases of DCL following HSCT for the treatment of severe aplastic anemia (SAA) have been described to date. In the present study, the case of a 25 year-old male patient diagnosed with SAA, who underwent a peripheral blood stem cell transplantation (PBSCT) using cells obtained from a sibling with an identical human leukocyte antigen, is presented. The patient developed acute myeloid leukemia with an $(8 ; 21)(\mathrm{q} 22 ; \mathrm{q} 22)$ translocation and an extra copy of the chromosome 8 in donor cells 2.5 years following PBSCT, which was preceded by the development of Graves' disease 1 year following PBSCT. The leukemia achieved complete remission following 1 cycle of priming therapy, 2 cycles of consolidation chemotherapy with daunorubicin and cytarabine and maintenance therapy with interleukin-2 (IL-2). At present, the patient has discontinued IL-2 therapy, and the DCL has been in molecular remission for $>3$ years. The present case indicates that chemotherapy and IL-2 maintenance therapy are an effective treatment for DCL; hyperthyroidism was relieved following treatment, although hypothyroidism subsequently developed.
\end{abstract}

\section{Introduction}

Donor cell leukemia (DCL) is a rare complication of hematopoietic stem cell transplantation (HSCT), in which normal donor cells become transformed into aggressive leukemia or myelodysplastic syndrome in the host environment (1). Common symptoms of DCL include anemia, neutropenia and thrombocytopenia (2). The latency between HSCT and DCL ranges between 1 and 193 months (median,

Correspondence to: Professor Ting Liu, Department of Hematology, West China Hospital, Sichuan University, 37 Guoxue Street, Chengdu, Sichuan 610041, P.R. China

E-mail: tingliuhx@126.com

Key words: donor cell leukemia, stem cell leukemia, severe aplastic anemia
24 months) (2). Reinduction chemotherapy or/and a second HSCT are the main treatments for DCL (3). The majority of case reports that are concerned with DCL report poor prognosis for patients even following a second HSCT (2). Wiseman reported that $53 \%$ of patients succumb to the disease, with a median survival time of 5.5 months after DCL diagnosis (3). Furthermore, the mean overall survival time for treated patients is 32.8 months (3). To date, $>60$ cases of DCL have been reported in the English literature (3), but only two cases of DCL following HSCT for the treatment of SAA have been described previously $(4,5)$. In the current study, the case of a 25 year-old male patient who developed acute myeloid leukemia (AML) with an $(8 ; 21)(\mathrm{q} 22 ; \mathrm{q} 22)$ translocation and an extra copy of the chromosome 8 in donor cells 2.5 years following peripheral blood stem cell transplantation (PBSCT) for SAA is presented. In addition, the onset of AML was preceded by the development of Graves' disease, which occurred 1 year subsequent to PBSCT. The patient was successfully treated with chemotherapy and IL-2 maintenance, which may be a unique treatment for DCL.

\section{Case report}

In December 2008, a 25 year-old male patient presented to the West China Hospital (Chengdu, China) with petechiae and fatigue. A complete blood count revealed pancytopenia with hemoglobin levels of $55.00 \mathrm{~g} / 1$ (normal range: $130 \sim 175 \mathrm{~g} / \mathrm{L}$ ), a reticulocyte count of $12.10 \times 10^{9}$ cells/1 (normal range: $24 \sim 84 \times 10^{9}$ cells/1), a platelet count of $6.00 \times 10^{9}$ cells/1 (normal range: $100 \sim 300 \times 10^{9}$ cells/1) and a white cell count of $1.90 \times 10^{9}$ cells $/ 1$ (normal range: $3.5 \sim 9.5 \times 10^{9}$ cells $/ 1$ ). The absolute neutrophil count was $0.38 \times 10^{9}$ cells/ 1 (normal range: $1.8 \sim 6.3 \times 10^{9}$ cells/1). Physical examination was normal, with the exception of pallor and petechiae. Serological tests for viral infections, including hepatitis $\mathrm{B}$ and $\mathrm{C}$, human immunodeficiency virus, toxoplasmosis, rubella, cytomegalovirus, herpes simplex virus and Epstein-Barr virus were negative. A bone marrow smear exhibited marked hypoplasia, and mainly contained lymphocytes and mature plasma cells. Bone marrow biopsy revealed that the majority of hematopoietic tissue had been replaced by fat tissue. Furthermore, no megakaryocytes were identified on the bone marrow smear or biopsy specimens. Flow cytometry analysis of cluster of differentiation (CD)55 and CD59 expression was normal. Humoral and cellular immunity tests indicated no 
autoimmune disease. Subsequently, idiopathic SAA was diagnosed.

The patient was administered cyclosporine (300 mg orally, daily; Huadong Medicine Co., Ltd., Hangzhou, China) for 2 months, however no response was achieved. Allogeneic-PBSCT (allo-PBSCT) was subsequently performed using cells obtained from the patient's 28 year-old brother. The patient's sibling was demonstrated to be clinically healthy and shared an identical human leukocyte antigen (HLA) with the patient. The patient was conditioned for 3 days with a total dose of $500 \mathrm{mg}$ rabbit anti-thymocyte globulin, followed by treatment with cyclophosphamide $(3,000 \mathrm{mg}$ intravenously, daily; Chengdu Suncadia Pharmaceuticals Co., Ltd., Chengdu, China) for 4 days. Prophylactic treatment with cyclosporine, methotrexate and $\gamma$-globulin was administered to prevent rejection and graft versus host disease (GVHD). A total of $2.30 \times 10^{6}$ peripheral stem cells $/ \mathrm{kg}$ were infused. Granulocyte-colony stimulating factor (G-CSF; $300 \mu \mathrm{g}$, daily) was administered 2 weeks preceding and 2 weeks following stem cell infusion. A bone marrow examination on day 28 following stem cell infusion indicated trilineage hematopoiesis. In addition, bone marrow engraftment analysis using multiplex polymerase chain reaction (PCR) of short tandem repeat (STR) markers was performed using a STR Typer-10G kit (Codon Ltd., Zhuhai, China). The PCR was performed in an Eppendorf AG 22331 Thermocyler (Eppendorf, Hamburg, Germany) and GeneMapper ${ }^{\circledR}$ ID version 3.2 (Thermo Fisher Scientific, Inc., Waltham, MA, USA) was used to interpret the results. PCR was performed under the following conditions: Five cycles of initial denaturation at $95^{\circ} \mathrm{C}$ for $2 \mathrm{~min}$ and $94^{\circ} \mathrm{C}$ for $30 \mathrm{sec}$, annealing at $61^{\circ} \mathrm{C}$ for $60 \mathrm{sec}$ and extension at $70^{\circ} \mathrm{C}$ for $60 \mathrm{sec}$, followed by 25 cycles of denaturation at $92^{\circ} \mathrm{C}$ for $30 \mathrm{sec}$, annealing at $61^{\circ} \mathrm{C}$ for $60 \mathrm{sec}$ and extension at $70^{\circ} \mathrm{C}$ for $60 \mathrm{sec}$, with a final extension step at $60^{\circ} \mathrm{C}$ for $45 \mathrm{~min}$. The results of the PCR revealed complete engraftment by donor cells (Fig. 1). Cyclosporine treatment was gradually reduced, and was discontinued 5 months following allo-PBSCT, as the patient exhibited no symptoms of GVHD. Periodic monitoring revealed that the patient's complete blood count was normal.

In April 2009, one year following allo-PBSCT, the patient presented to the West China Hospital with fatigue, palpitation and increased appetite. Physical examination indicated a diffuse goiter and tachycardia. Laboratory findings revealed elevated levels of free thyroxine (T4; $29.22 \mathrm{pmol} / \mathrm{l}$; normal range, 12-22 pmol/1), decreased levels of thyroid stimulating hormone (TSH; <0.005 mU/1; normal range, 0.27-4.2 mU/l) and high levels of antithyrotrophin receptor $(1,329 \mathrm{IU} / \mathrm{ml}$; normal range, $<115 \mathrm{IU} / \mathrm{ml})$ and antithyroid peroxidase $(184.3 \mathrm{IU} / \mathrm{ml}$; normal range, $<34 \mathrm{IU} / \mathrm{ml}$ ) antibodies. Complete blood count was normal. In consequence, Graves' disease was diagnosed. Oral propylthiouracil (200 mg, daily for 3 months; Fosun International, Shanghai, China) and thiamazole (20 mg, daily for 9 months; Merck KGaA, Darmstadt, Germany) were administered discontinuously to treat the disease for 1 year. Initially, the symptoms were alleviated, and then recurred. The levels of free T4 and TSH were not well controlled. Radioactive iodine therapy was suggested, and treatment with antithyroid drugs was stopped in preparation for iodine therapy. However, the patient felt well, and refused further treatment with iodine therapy or antithyroid drugs.
In October 2011, 6 months after the treatment with antithyroid drugs had been discontinued, and 2.5 years subsequent following allo-PBSCT, the patient presented the West China Hospital with petechiae, hyperhidrosis and low-grade fever. Complete blood count revealed pancytopenia with hemoglobin levels of $106.00 \mathrm{~g} / \mathrm{l}$, a platelet count of $19.00 \times 10^{9}$ cells $/ 1$ and a white cell count of $2.20 \times 10^{9}$ cells/ 1 without leukemia cells. High levels of free T4 and low levels of TSH indicated hyperthyroidism. A bone marrow smear revealed an active proliferation of nucleated cells with numerous myeloblasts, accounting for $45.5 \%$ of the total blood cell count. Peroxidase stain was positive in $97.0 \%$ of myeloblasts, whereas Periodic acid-Schiff and non-specific esterase stains were negative. Flow cytometry of leukemic cells revealed positivity for CD34, HLA-DR, CD117, CD13 and cytoplasmic myeloperoxidase with partial expression of CD56. These results indicated a typical cell surface antigen expression pattern for AML with maturation [previously designated as AML M2, according to the French-American-British (FAB) classification of AML (6)]. Cytogenetic analysis identified an $(8 ; 21)(\mathrm{q} 22 ; \mathrm{q} 22)$ translocation and an extra copy of the chromosome 8 (Fig. 2). Screening for fusion genes revealed positivity for AML1/eight twenty one fusion protein and negativity for core binding factor $\beta /$ myosin, heavy chain 11 , smooth muscle. No mutations were identified in the feline sarcoma-related tyrosine kinase 3/internal tandem duplication, c-Kit, nucleophosmin and CCAAT/enhancer-binding protein alpha genes. Engraftment analysis of the bone marrow and peripheral blood revealed complete engraftment by donor cells (Fig. 1). The donor remained healthy, without evidence of viral infection. A bone marrow smear, cytogenetic analysis and screening for the aforementioned fusion genes and mutations in the donor indicated normality. Subsequently, the patient was diagnosed with AML with an $(8 ; 21)(\mathrm{q} 22 ; \mathrm{q} 22)$ translocation and an extra copy of the chromosome 8 of donor origin. Complete hematological and molecular remission was achieved following a single cycle of priming therapy. Two cycles of consolidation chemotherapy with DA $\left[45 \mathrm{mg} / \mathrm{m}^{2}\right.$ intravenous daunorubicin (Zheijiang Hisun Chemical Co., Ltd., Taizhou, China), days 1-3; and $100 \mathrm{mg} / \mathrm{m}^{2}$ intravenous cytarabine (Sinopharm A-Think, Changchun, China), days 1-7] were administered, followed by maintenance therapy with recombinant interleukin-2 (IL-2; Shandong Quangang Pharmaceutical Co., Ltd., Jinan, China). The IL-2 was injected subcutaneously at a dose of 1,000,000 U daily for 10 days every month, and then tapered every 6 months. In October 2014 the patient stopped receiving IL-2. A bone marrow examination is performed on the patient every year at the West China Hosptial, and DCL has been in molecular remission for 3 years. Notably, hyperthyroidism was relieved following treatment; however, hypothyroidism subsequently developed, and consequently, continuous treatment with oral Euthyrox $^{\circledR}(50 \mu \mathrm{g}$, daily; Merck KGaA) was administered.

Written informed consent was obtained from the patient for the use of patient information and accompanying images in this study.

\section{Discussion}

The first case of DCL was reported in 1971 (7), and to date, $>60$ cases have been reported (3). The European Group for Blood and Marrow Transplantation reported that the 

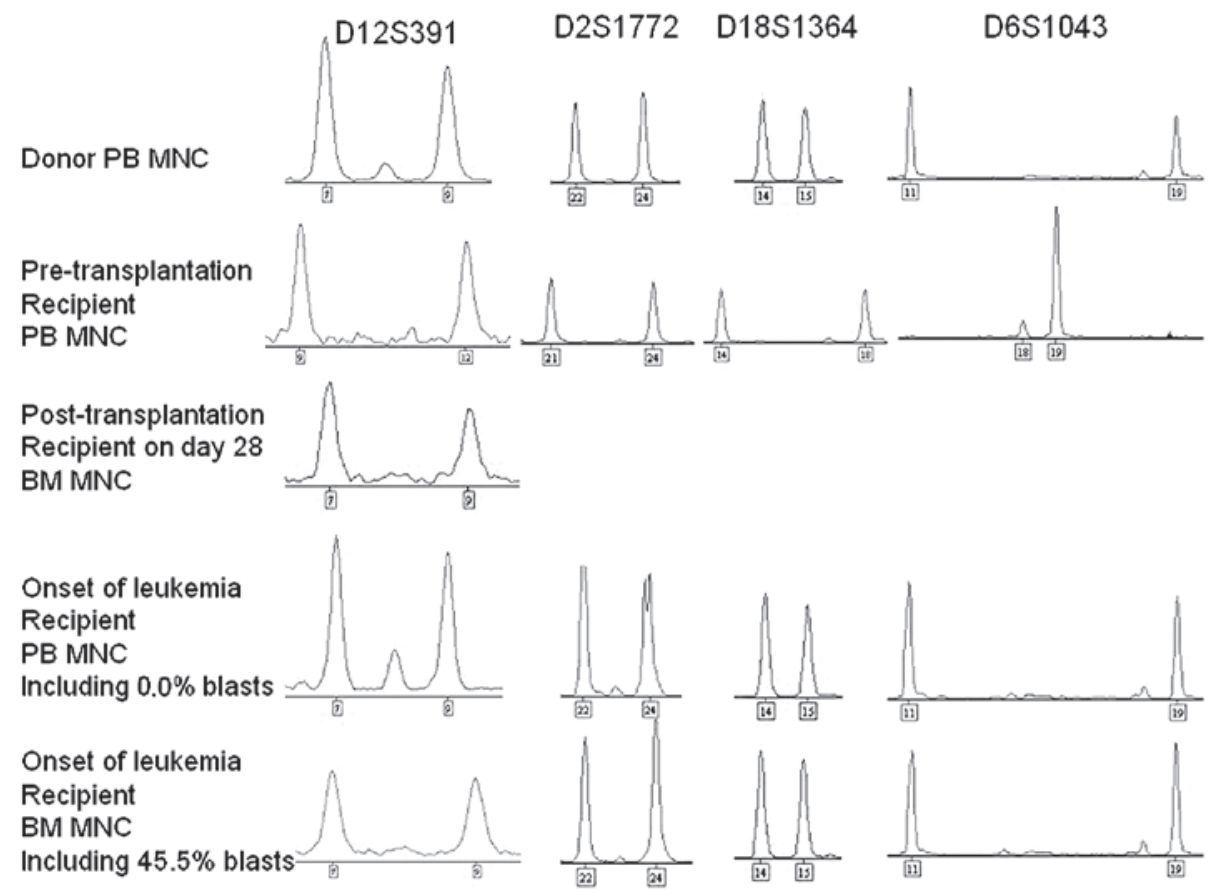

Figure 1. Engraftment analysis of donor/host chimerism. Genomic DNA was obtained from the peripheral blood or bone marrow mononuclear cells, and amplified using PCR with 6 sets of fluorescently-labeled oligonucleotide primers specific for particular nucleotides of STR markers. A single chromosome 12 STR marker (D12S391) wass identified by capillary electropherograms of PCR amplification. To further confirm the origin of leukemia, another three informative satellite markers (D2S1772, D18S1364 and D6S1043) were identified as shown. Below each peak, the number of repeats is provided. Since the specimen collected on postoperative day 28 following peripheral blood stem cell transplantation was not conserved, no results were acquired for the latter three markers. $\mathrm{PB}$, peripheral blood; MNC, mononuclear cells; BM bone marrow; PCR, polymerase chain reaction; STR, short tandem repeat.

\section{H}

1

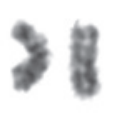

6

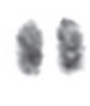

13
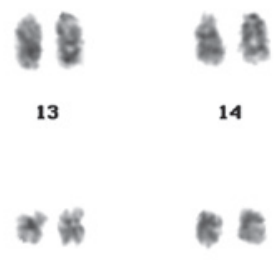

19
14

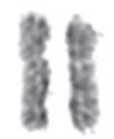

2

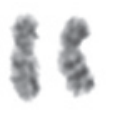

7

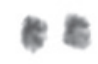

20

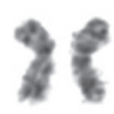

3

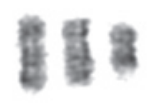

8

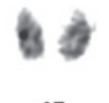

15

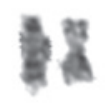

9

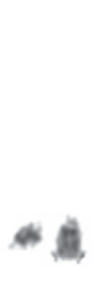

21
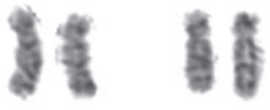

4

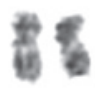

11
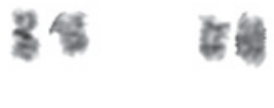

17

16

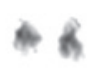

22
12

18

5
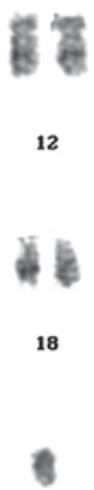

$\mathbf{Y}$

Figure 2. G-band karyotyping of recipient bone marrow cells indicates chromosomal abnormality, with $47, \mathrm{XY},+8, \mathrm{t}(8 ; 21)(\mathrm{q} 22 ; \mathrm{q} 22)$ observed in 18 of the 20 cells analyzed.

incidence of DCL in allo-HSCT recipients is $\sim 0.1 \%$ (8). Recently, Wiseman (3) proposed that, in a number of cases, DCL may remain undiagnosed for several years, and may account for $\leq 5 \%$ of all leukemia relapses post-HSCT. The primary diagnosis in the majority of DCL cases is leukemia (3). Prior to the present case, only 2 cases of DCL and 2 cases of donor cell-derived myelodysplastic syndrome (DCM) following HSCT for SAA have been reported in the English literature to date $(4,5,9,10)$. The 2 cases of DCL were diagnosed as AML (M5a and M0, respectively, according to 
the FAB classification of AML) on days 319 and 208, respectively, following bone marrow transplantation. The 2 cases of DCM occurred 2 and 13 years following HSCT. Of these cases, $\geq 3$ patients have succumbed to the disease, whereas all donors were healthy at the time of publication of the present report.

Currently, a number of methods are available to confirm the origin of donor cells, including conventional cytogenetics, fluorescent in situ hybridization and molecular DNA markers, such as variable number tandem repeats, STRs and restriction fragment length polymorphisms (11). Due to the high sensitivity and availability of commercial multiplex kits, STRs amplified by PCR are considered the gold standard technique for analyzing DCL cases $(2,11)$. Due to the extensive use of molecular analysis of donor/host chimerism, an increasing number of DCL cases have been reported; since 2004, more cases of DCL have been reported than the total number of cases reported in the previous 34 years (3). In the current case, using this highly sensitive technique, $45.5 \%$ blast cells were identified in the bone marrow of the patient, and the complete blood count of donor origin was demonstrated to be identical to that from peripheral blood, which confirmed the diagnosis of DCL following allo-PBSCT for SAA.

A number of mechanisms have been proposed to explain the etiology of DCL, including abnormality in donor cells (such as occult leukemia or preleukemic potential), conditioning or virus-induced mutagenesis or transformation, impaired immune surveillance or defective microenvironmental niche in the host $(3,11,12)$. To date, multiple factorial processes have been considered to be the main cause of DCL $(3,11,12)$. In the present case, the donor was completely healthy prior to PBSCT and when the recipient developed DCL. Screening tests identified no evidence of immunological disease, viral infection or genetic mutations in the donor. These results suggest that the donor cells exhibited no abnormalities. Certain authors have reported that long-term use of immunosuppressive agents or G-CSF for the treatment of SAA are risk factors for the development of therapy-related AML/myelodysplasia, which is usually a late complication (13-17). In the current case, the patient exhibited a rapid hematopoietic recovery following PBSCT, and exhibited no evidence of GVHD. Furthermore, short-term treatment with immunosuppressive agents and G-CSF did not appear to affect donor cells. Previously, it has been hypothesized that malignant cells are continuously arising in healthy individuals, but the immune system is able to recognize and eliminate such cells via complex interactions (3). Therefore, the development of DCL may be the result of impaired immune surveillance and an acquired $(8 ; 21)(\mathrm{q} 22 ; \mathrm{q} 22)$ translocation with an extra copy of the chromosome 8 in donor cells. The latter may spontaneously arise in a clone or may be induced by the impaired stem cell niche, which is involved in the regulation of quiescence, self-renewal, proliferation and differentiation of stem cells $(18,19)$. The impaired immune surveillance leads to anergy towards the arising malignant clones, which are favored by the immunocompromised status following transplantation $(3,11)$. Consequently, it is possible to hypothesize that the development of DCL in the present case may be predominantly attributed to impaired immune surveillance and an abnormal hemopoietic microenvironment.

The prognosis of DCL is usually poor, with a median survival time of 5.5 months (range, 1 week-64 months) following DCL diagnosis. A second HSCT is the main treatment for DCL (3), however, in the present case, only 2 cycles of DA consolidation chemotherapy were administered subsequent to induction, followed by maintenance therapy with IL-2. IL-2 is a cytokine signaling molecule within the immune system that regulates lymphocyte activity. It enhances the anti-tumor effect of macrophages through the induction of cytokines with anti-neoplastic activity, including $\alpha$-tumor necrosis factor and $\gamma$-interferon (20). Recombinant IL-2 binds to IL-2 receptors, and introduces the diphtheria toxin into the cells that express those receptors, thus killing the malignant cells that express the IL-2 receptor. This indicates that IL-2 is an effective drug for DCL maintenance therapy.

In conclusion, the present study highlights DCL as a rare complication of allo-PBSCT for SAA, and indicates that impaired immune surveillance is an important mechanism of leukemogenesis. Furthermore, the current case demonstrates that treatment with recombinant IL-2 is effective as a maintenance therapy for DCL.

\section{References}

1. Sala Torra O and Loeb KR: Donor cell-derived leukemia and myelodysplastic neoplasm: Unique forms of leukemia. Am J Clin Pathol 135: 501-504, 2011.

2. Wang E, Hutchison CB, Huang Q, Lu CM, Crow J, Wang FF, Sebastian S, Rehder C Lagoo A, Horwitz M, et al: Donor cell-derived leukemias/myelodysplastic neoplasms in allogeneic hematopoietic stem cell transplant recipients: A clinicopathologic study of 10 cases and a comprehensive review of the literature. Am J Clin Pathol 135: 525-540, 2011.

3. Wiseman DH: Donor cell leukemia: A review. Biol Blood Marrow Transplant 17: 771-789, 2011.

4. Browne PV,Lawler M, Humphries P and McCann SR: Donor-cell leukemia after bone marrow transplantation for severe aplastic anemia. N Engl J Med 325: 710-713, 1991.

5. Lawler M, Locasciulli A, Longoni D, Schiro R and McCann SR: Leukaemic transformation of donor cells in a patient receiving a second allogeneic bone marrow transplant for severe aplastic anaemia. Bone Marrow Transplant 29: 453-456, 2002.

6. Catovsky D, Matutes E, Buccheri V, Shetty V, Hanslip J, Yoshida N and Morilla R: A classification of acute leukaemia for the 1990s. Ann Hematol 62: 16-21, 1991.

7. Fialkow PJ, Thomas ED, Bryant JI and Neiman PE: Leukaemic transformation of engrafted human marrow cells in vivo. Lancet 1: 251-255, 1971 .

8. Hertenstein B, Hambach L, Bacigalupo A, Schmitz N, McCann S, Slavin S, Gratwohl A,Ferrant A, Elmaagacli A, Schwertfeger R, et al; Chronic Leukaemia Working Party of the European Group for Blood and Marrow Transplantation: Development of leukemia in donor cells after allogeneic stem cell transplantation - a survey of the European Group for Blood and Marrow Transplantation (EBMT). Haematologica 90: 969-975, 2005.

9. Hashino S, Fujisawa F, Kondo T, Imamura M, Sato K, Torimoto Y, Kohgo Y, Kimura K, Furukawa H, Todo S and Asaka M: Donor-type myelodysplastic syndrome with $\mathrm{t}(2 ; 3)$ and monosomy 7 after allogeneic peripheral blood stem cell transplantation and liver transplantation in a patient with severe-type aplastic anemia. Int J Hematol 84: 363-366, 2006.

10. Haltrich I, Müller J, Szabó J, Kovács G, Kóos R, Poros A, Dobos $\mathrm{M}$ and Fekete G: Donor-cell myelodysplastic syndrome developing 13 years after marrow grafting for aplastic anemia. Cancer Genet Cytogenet 142: 124-128, 2003.

11. Ruiz-Argüelles GJ, Ruiz-Argüelles A and Garcés-Eisele J: Donor cell leukemia: A critical review. Leuk Lymphoma 48: 25-38, 2007. 
12. Flynn CM and Kaufman DS: Donor cell leukemia: Insight into cancer stem cells and the stem cell niche. Blood 109: 2688-2692, 2007.

13. Socié G, Henry-Amar M, Bacigalupo A, Hows J, Tichelli A, Ljungman P, McCann SR, Frickhofen N, Van't Veer-Korthof E and Gluckman E; European Bone Marrow Transplantation-Severe Aplastic Anaemia Working Party: Malignant tumors occurring after treatment of aplastic anemia. N Engl J Med 329: 1152-1157, 1993.

14. Kojima S, Ohara A, Tsuchida M, Kudoh T, Hanada R, Okimoto Y Kaneko T, Takano T, Ikuta K and Tsukimoto I; Japan Childhood Aplastic Anemia Study Group: Risk factors for evolution of acquired aplastic anemia into myelodysplastic syndrome and acute myeloid leukemia after immunosuppressive therapy in children. Blood 100: 786-790, 2002.

15. Saracco P, Quarello P, Iori AP, Zecca M, Longoni D, Svahn J, Varotto S, Del Vecchio GC, Dufour C, Ramenghi U, et al; Bone Marrow Failure Study Group of the AIEOP (Italian Association of Paediatric Haematology Oncology): Cyclosporin A response and dependence in children with acquired aplastic anaemia: A multicentre retrospective study with long-term observation follow-up. Br J Haematol 140: 197-205, 2008.
16. Kaito K, Kobayashi M, Katayama T, Masuoka H, Shimada T, Nishiwaki K, Sekita T, Otsubo H, Ogasawara Y and Hosoya T: Long-term administration of G-CSF for aplastic anaemia is closely related to the early evolution of monosomy 7 MDS in adults. Br J Haematol 103: 297-303, 1998.

17. Witherspoon RP, Fisher LD, Schoch G, Martin P, Sullivan KM, Sanders J, Deeg HJ, Doney K, Thomas D, Storb R and Thomas ED: Secondary cancers after bone marrow transplantation for leukemia or aplastic anemia. N Engl J Med 321: 784-789, 1989.

18. Moore KA and Lemischka IR: Stem cells and their niches. Science 311: 1880-1885, 2006.

19. Li Z and Li L: Understanding hematopoietic stem-cell microenvironments. Trends Biochem Sci 31: 589-595, 2006.

20. Zhang SR, Salup RR, Urias PE, Twilley TA, Talmadge JE, Herberman RB and Wiltrout RH: Augmentation of NK activity and/or macrophage-mediated cytotoxicity in the liver by biological response modifiers including human recombinant interleukin 2. Cancer Immunol Immunother 21: 19-25, 1986. 